\title{
Phenotypic Determination and Characterization of Nestin-Positive Precursors Derived from Human Fetal Pancreas
}

\author{
Haixia Huang and Xueming Tang \\ Department of Cell Biology, Shanghai Second Medical University, Shanghai, China
}

SUMMARY: Demand for donations to meet the requirements of pancreas or islet transplantation has prompted the search for alternative sources of $\beta$-cell replacement therapy. Earlier studies identified nestin-positive islet-derived progenitor cells (NIPs) residing in human pancreas. In the present study, we isolated and cultured human fetal NIPs that express stem cell marker ABCG2/BCRP1. In confluent cultures, NIPs formed three-dimensional islet-like cell clusters (ICCs). During differentiation, NIP-derived ICCs showed numerous pancreatic lineage transcripts including insulin, whereas ABCG2 and nestin expression fell concomitantly. In addition, ICCs displayed the ability to reverse hyperglycemia in diabetic NOD-SCID mice, as well as infiltrate and form well-differentiated structures in normal mice. These cells can be cloned repeatedly and maintained in long-term culture. Our studies are the first to show NIPs derived from human fetal pancreas, which may have significant implications for future applications in stem cell therapy of diabetes. (Lab Invest 2003, 83:539-547).

$T$ ype 1 diabetes is a multisystem disease resulting from autoimmune destruction of pancreatic islet $\beta$ cells. The most widely used treatment for type 1 diabetes is insulin injection, but this modality does not avoid many of the most common diabetic complications. In some cases, pancreatic or islet cell transplant is effective, but widespread application is limited by a shortage of available insulin-producing tissues. $\beta$ cells in a normal adult rat have a life span of approximately 50 days (Finegood et al, 1995). Maintenance of blood glucose level requires $\beta$-cell neogenesis from pancreatic stem cells. Neogenesis was induced experimentally by several methods, including partial pancreatectomy, specific growth factor, and wrapping the head of the pancreas in cellophane (Bonner-Weir et al, 1993; Otonkoski et al, 1994; Rosenberg and Vinik, 1992). The ability to stimulate the growth and differentiation remains a significant scientific and clinical interest, and pancreatic stem cells may lead to numerous clinical benefits, including stem cell therapy for type 1 diabetes.

There have been a number of reports on the "elusive pancreatic stem cell" (Arias and Bendayan, 1993; Bonner-Weir et al, 2000; Cornelius et al, 1997; Schwitzgebel et al, 2000; Zulewski et al, 2001); however, a definitive molecular marker remains obscure. Some reports hold that stem cells exist in duct structures, based on the observation of islet neogenesis from duct structures in these areas in vivo (Gmyr et al,

DOI: 10.1097/01.LAB.0000062890.40534.1C

Received January 18, 2003.

Address reprint requests to: Dr. Xueming Tang, Department of Cell Biology, Shanghai Second Medical University, 280 Chongqing South Road, Shanghai, 200025, China. E-mail: xmtang@shsmu.edu.cn
2000; Rosenberg, 1995). Others showed the possibility of intra-islet stem cells (Fernandes et al, 1997; Guz et al, 2001), as it is known that islet implantation has a long-term curative effect. Recently the intermediate filament protein nestin, a neural stem cell marker (Lendahl et al, 1990), was found to be expressed in pancreas (Hunziker and Stein, 2000). These nestinpositive islet-derived progenitor cells (NIPs) were isolated from rat and adult human pancreases and were found to be multipotential stem cells (Zulewski et al, 2001). Furthermore, a recent study that aimed at inducing the differentiation of ES cells into pancreatic $\beta$ cells achieved the production of islet-like cells from nestin-positive precursors (Lumelsky et al, 2001). Similar stem cells that could reverse diabetes in mice were isolated from prediabetic mice and transdifferentiated hepatic stem cells (Cornelius et al, 1997; Ramiya et al, 2000; Yang et al, 2002). However, no study has been reported on human fetal NIPs. In the present report, we present in vitro and in vivo experiments with NIPs derived from human fetal pancreas. Our study suggests promising implications for theoretical and clinical applications of pancreas regeneration.

\section{Results}

\section{In Vitro Growth and Phenotype Determination of Human Fetal NIPs}

To identify the composition of ducts and primary cell clusters in human fetal pancreas, we conducted immunofluorescence studies in primary culture. Three types of adherent cells were identified: large cells immunopositive for CK19 characterize the pancreatic ducal epithelium (Fig. 1A), insulin-positive $\beta$ cells are found in patches with endocrine granules on one side 


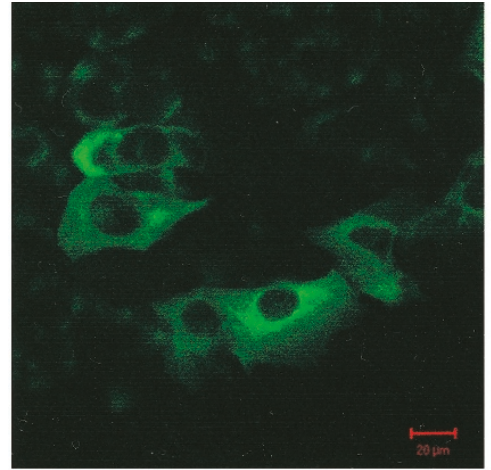

A

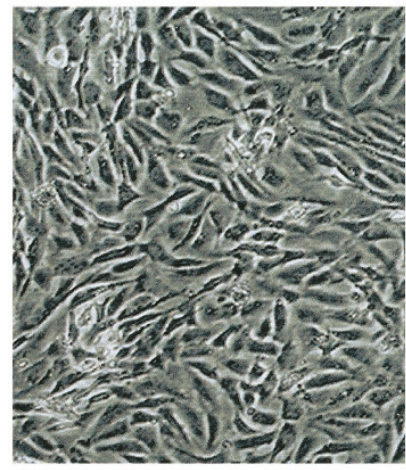

D

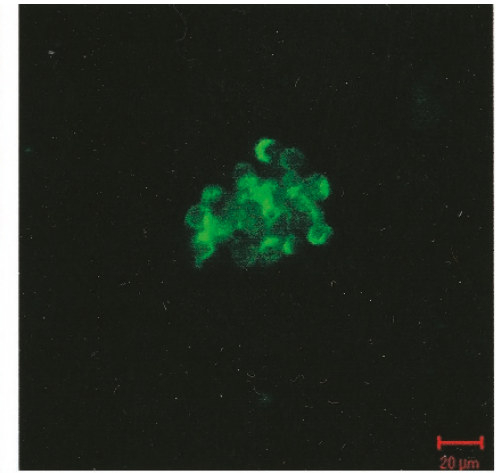

B

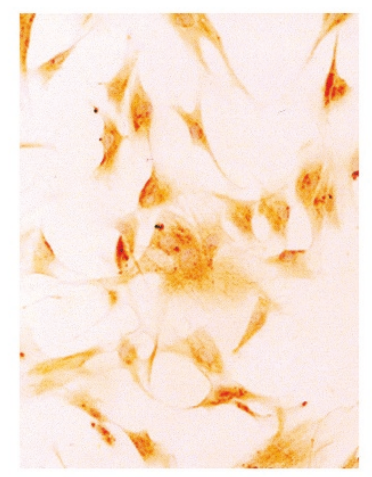

$\mathrm{E}$

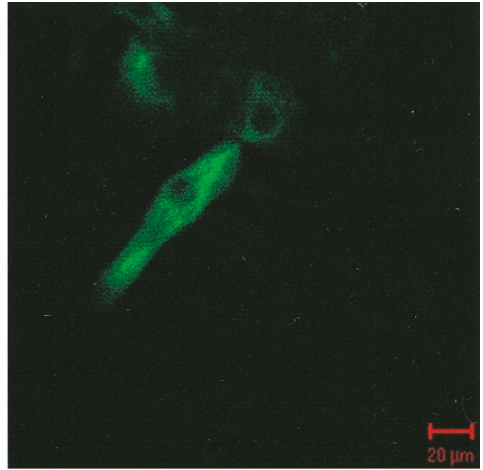

$\mathrm{C}^{\prime}$

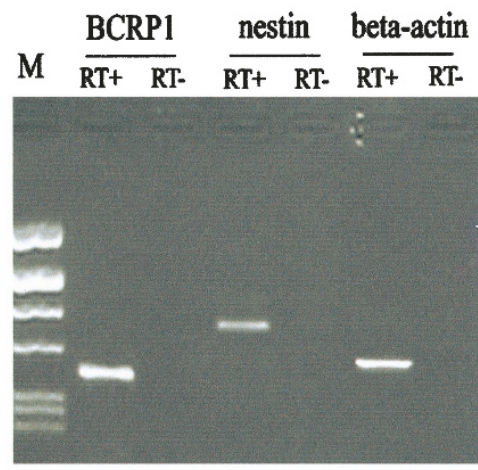

F

\section{Figure 1.}

A to C, Composition of adherent cells after ducts and cell clumps flattened into monolayer in primary culture. A, CK19-positive cells are epithelium like. B, Small cells in patches stained for insulin. C, Nestin-positive cells are scattered and infrequent (magnification bars $=20 \mu \mathrm{m}$ ). D to $\mathrm{F}$, Phenotypic determination of human fetal NIPs. D, Monolayer appearance of plaques of human fetal NIPs formed 2 to 3 days after selection $(40 \times)$. E, NIPs maintained their stellate-like appearance and immunopositive for nestin $(200 \times)$. F, RT-PCR analysis of NIP cultures showed high transcription levels of stem cell markers nestin and ABCG2.

of the cytoplasm (Fig. 1B), and stellate nestinexpressing cells are infrequent and always grow in a scattered manner (Fig. 1C). Monolayer plaques of cells formed in EHAA medium were incubated for approximately 4 weeks in the glucose-free medium with $0.5 \%$ fetal bovine serum (FBS). After this selection procedure, only a few stellate cells remained and scattered on the surface of flasks. To stimulate the growth of NIPs, we added $20 \mathrm{ng} / \mathrm{ml}$ basic fibroblast growth factor (bFGF) and $5.6 \mathrm{~mm}$ glucose into the culture medium. Cells underwent rapid proliferation and formed cell plaques in 2 to 3 days (Fig. 1D). Because the residual cells are so infrequent, we consider each plaque to be the progeny of a single cell. Cells in individual plaques were subcloned by removing some cells into a fresh culture dish containing identical medium. These cells maintained their stem cell-like phenotype, expressing nestin (Fig. 1E). In addition, a high level of the stem cell-specific gene ABCG2/ BCRP1 was detected by RT-PCR (Fig. 1F). Upon reaching $75 \%$ to $90 \%$ confluence, the cultures were split to maintain them in long-term culture.

\section{In Vitro Differentiation of Human Fetal NIPs}

NIPs will eventually self-assemble to form islet-like cell clusters (ICCs) if the cultures are not split. According to development levels, ICCs will undergo three stages of differentiation.

Stage 1: NIPs Self-Assemble to Form ICCs. After NIPs reached $80 \%$ confluence, cells began to migrate and form small transparent ICCs lying on top of NIPs (Fig. 2A). This procedure typically took 10 days but is reduced to 4 to 5 days when $10 \%$ horse serum is added. We subcloned some ICCs by placing them into 24-well plates individually, allowing them to repeat the process. Cells migrated from ICCs and became confluent by 2 to 3 days. This process was repeated several times and proved to be highly reproducible. Immunohistochemistry assays revealed that newly formed ICCs were immature and composed predominantly of undifferentiated nestin-positive cells (Fig. 2B). No insulin or glucagon expression was found despite high levels of $A B C G 2$ and $c-M E T$ transcripts (Fig. 2G). Three-dimensional ICC structures formed at this stage may provide interesting evidence for further differentiation.

Stage 2: Differentiation of NIPs into Cells of Diverse Phenotypes. After subcloning, ICCs were incubated for 2 weeks in DMEM/F12 medium plus 10\% horse serum and $10 \%$ FBS without bFGF. ICCs were enlarged and denser than that of stage 1 (Fig. 2C), and their number increased to 3 to $4 \times 10^{3}$ per $25-\mathrm{cm}^{2}$ 


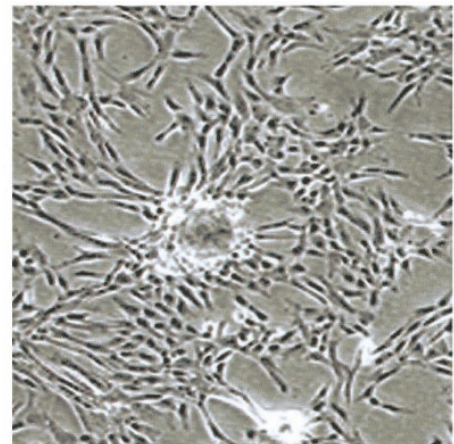

A

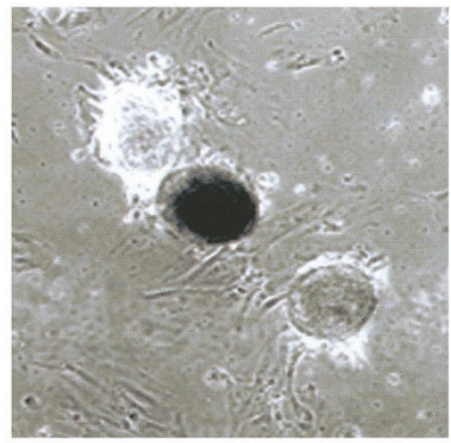

C

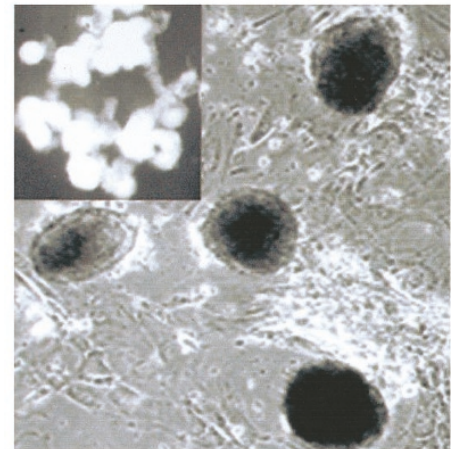

E

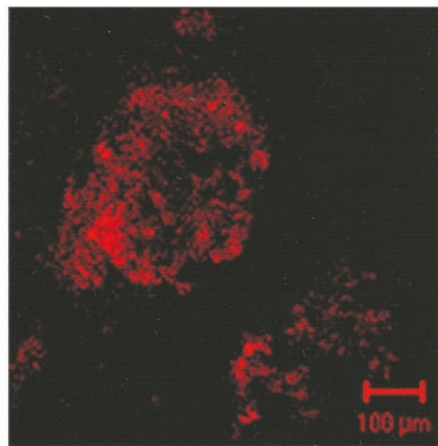

B

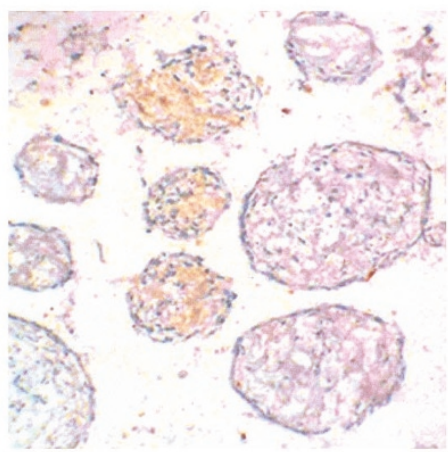

D

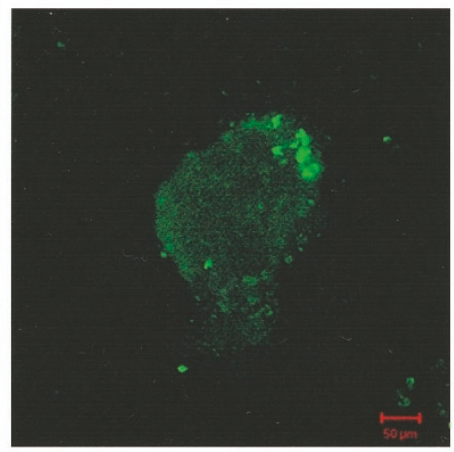

F

\section{stagel stage2 stage3}

RT+ RT- RT+ RT- RT+ RT-
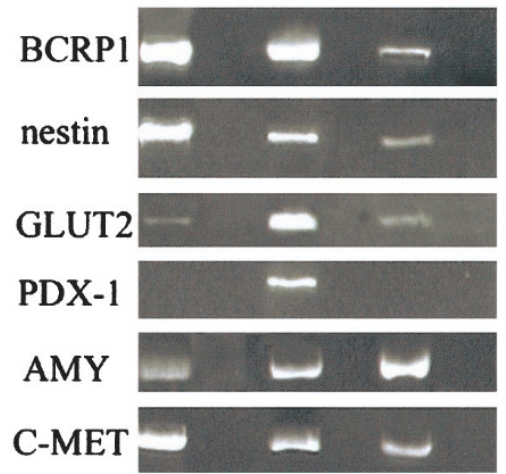

HGF

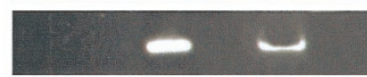

CK19

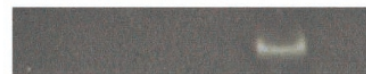

insulin

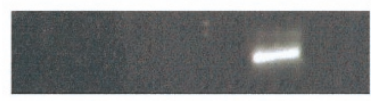

somatostatin

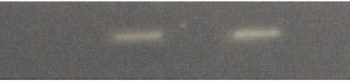

NKX6.1

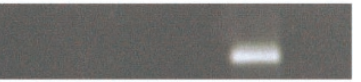

Isl1

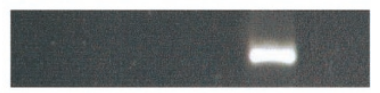

beta-actin

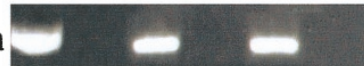

G

\section{Figure 2.}

Increased differentiation of NIPS in ICCS. A, Upon confluence, NIPs began to form immature ICCS (40X). B, ICCS of stage 1 are primarily composed of NIPS, immunostaining for nestin $(\mathrm{bar}=100 \mu \mathrm{m})$. C, After bFGF was withdrawn, ICCs of stage 2 became much bigger and more compact after 2 weeks in FBS and HS $(40 \times)$. D, Glucagon expression in cells is close to the periphery but not in the center of ICCs of stage $2(100 \times)$. E, Incubation of ICCs of stage 2 with inductors for 10 days promoted an increase in number and size of ICCs containing more specialized cells formed at stage $3(40 \times)$, and many ICCs were detached to float in the medium (inset, 15×). F, Insulin-producing $\beta$ cells were detected in ICCs of stage 3 by immunoflurescent staining (magnification bar $=50 \mu \mathrm{m}$ ). G, RT-PCR analysis of pancreatic gene expression of ICCS, note that down-regulation of progenitor markers correlate with increasing expression of $\beta$-cell markers.

culture plate. In some cases, cells close to the periphery of ICCs expressed glucagon (Fig. 2D). There were still no insulin-positive cells in ICCs of this stage. Genes encoding the pancreatic differentiation markers PDX-1, GLUT-2, and HGF; endocrine markers glucagon and somatostatin; and exocrine marker $A M Y$ were activated in ICCs of this stage determined by RT-PCR (Fig. 2G). These results indicate that human fetal NIPs are multipotential like their adult counterpart; however, they can generate a variety of more specialized cell types.

Stage 3: Conversion of NIPs into $\beta$-Cell Phenotype. We next attempted to induce efficiently production of $\beta$ cells from NIPs. A survey of inductive factors for $\beta$ cells revealed that in addition to glucose, which stimulates their maturation, the combined effect of hepatocyte growth factor (HGF), nicotinamide, insulin growth factor (IGF), and betacellulin favor differentiation of NIPs toward $\beta$ cells. After ICCs of stage 2 were cultured for 10 days in DMEM/F12 (16.5 mm glucose) with above combined factors added, an increase in both the number and size of ICCs was observed with many detached and floating in the medium (Fig. 2E). Immunofluorescent staining showed that insulinpositive cells presented in ICCs (Fig. 2F), suggesting that $\beta$ cells have derived from NIPs. The analysis of mRNAs implicates that expressions of $\beta$-cell markers insulin, Nkx6.1, and Is/1 and duct cell marker CK19 


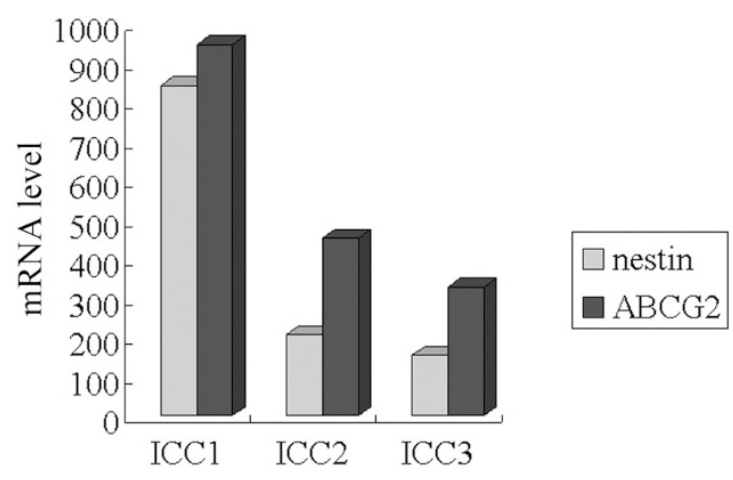

Figure 3.

Semiquantitative RT-PCR analysis of ABCG2 and nestin expression in ICCs of different stages. All values are taken from 30 cycle amplifications and are normalized to $\beta$-actin from the same sample. Note that differentiation of NIPS correlate well with the down-regulation of ABCG2 and nestin. (ICC1, ICCS of stage 1 ; ICC2, ICCs of stage 2 ; ICC3, ICCs of stage 3.)

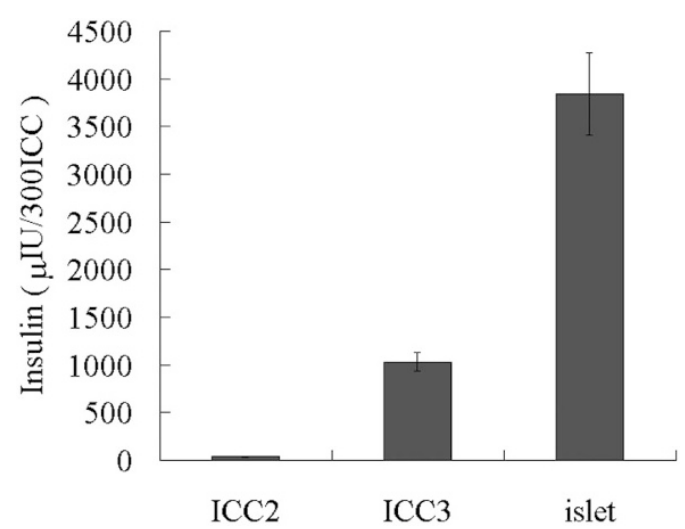

Figure 4.

Ability of NIP-derived ICCs to produce and store insulin. Note that intracellular insulin level of ICC3 is much higher than that of ICC2, while lower than that of human fetal islet ( $n=3$; ICC2, ICCs of stage 2; ICC3, ICCs of stage 3 ; islet, primarily cultured human islets).

present during this stage, whereas transcription level of $P D X-1$ is too low to be detected (Fig. 2G). It is interesting that NIP differentiation correlates well with the down-regulation of ABCG2 and nestin demon- strated by semiquantitative RT-PCR analysis (Fig. 3). In addition, $C-M E T$ and $A M Y$ maintained high levels of expression even at the third stage of differentiation.

As showed in Figure 4, intracellular insulin content in ICCs of stage 3 is much higher than that of stage 2 . However, this value of insulin level is still very low compared with that of human fetal islets, which indicate incomplete induction of NIPs. Further optimization of conditions is required to improve the efficiency of induction.

\section{Insulin Secretion in Response to Glucose}

For determining whether these insulin-positive cells could release insulin as do normal $\beta$ cells, ICCs of stage 3 were challenged by glucose as well as other secretagogues. As a result, glucose-challenged ICCs secreted a certain amount of insulin and this glucoseresponsive insulin secretion seems to take a dosedependent manner like primary pancreatic islets do in vitro (Fig. 5A). Furthermore, all of the secretagogues tested also induced insulin secretion in the presence of $5 \mathrm{~mm}$ glucose (Fig. 5B), which means that ICCs use normal pancreatic mechanisms to regulate insulin release.

\section{Preliminary In Vivo Studies of Human Fetal NIPs}

To investigate the ability of human fetal NIPs to reverse hyperglycemia, we implanted 500 ICCs into the subcapsular region of the left kidney of streptozotocin (STZ)-induced diabetic mice, and blood glucose levels were monitored at regular intervals. Four days after implantation, diabetic mice showed decreases in blood glucose (Fig. 6A). Seven days later, the average blood glucose level of the eight mice approached normal levels and was stable up to 40 days. In contrast, mice of the STZ group that did not receive ICCs showed persistent hyperglycemia. Statistical assay showed that implantation of ICCs achieved a significant decrease in blood glucose $(p<0.05)$. Histologic and immunohistochemical examinations revealed neovascularization and insulin-positive clusters in implanted sites (data not showed). These results
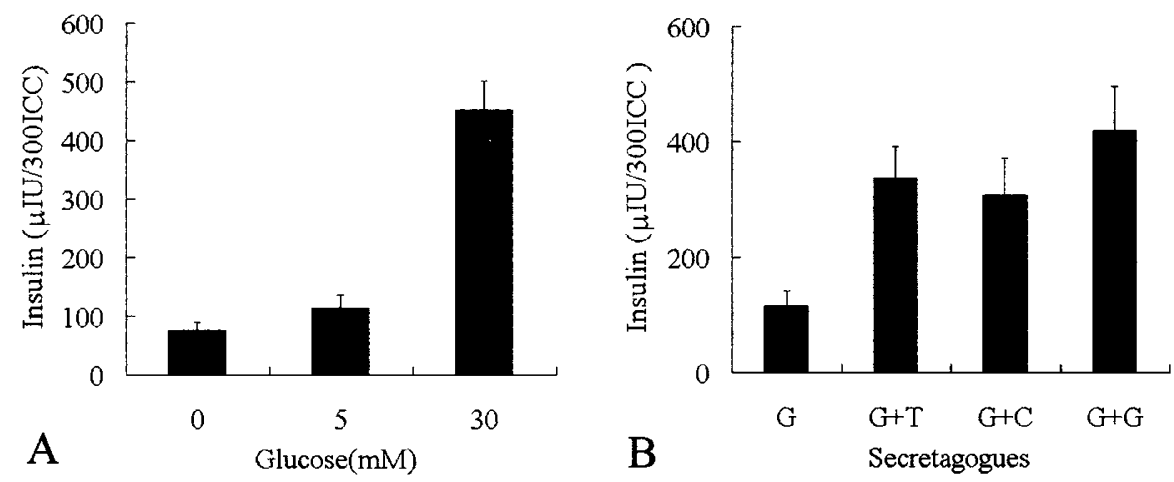

Figure 5.

ICCs of stage 3 release insulin in response to glucose and secretagogues. A, ICCs secrete insulin after glucose challenge, indicating functional $\beta$ cells in ICCs. B, Insulin release in response to various secretagogues in the presence of $5 \mathrm{~mm}$ glucose $(n=3 ; \mathrm{G}, 5 \mathrm{~mm}$ glucose; $\mathrm{G}+\mathrm{T}, 5 \mathrm{~mm}$ glucose $+1 \mathrm{~mm}$ tolbutamide; $\mathrm{G}+\mathrm{C}$, 5 mм glucose + 1 mм carbachol; G+G, 5 mm glucose + 1 mm GLP-1). 


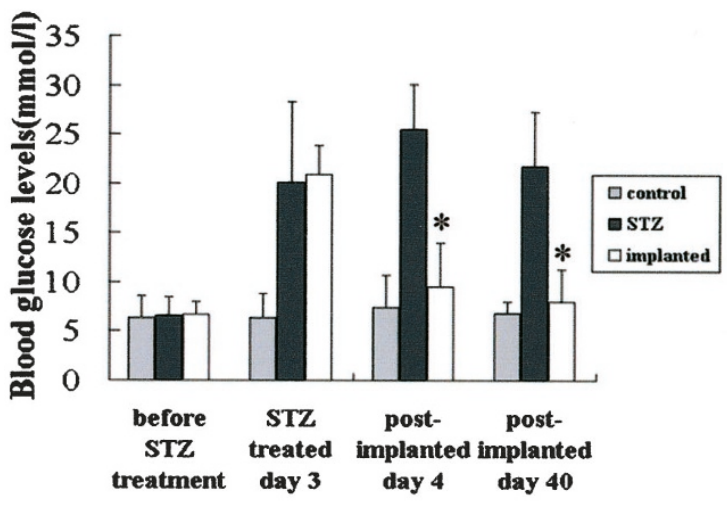

A

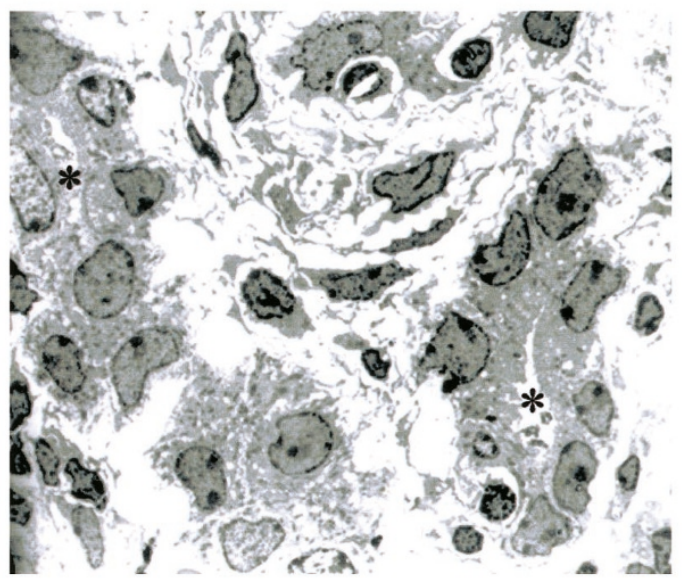

$\mathrm{C}$

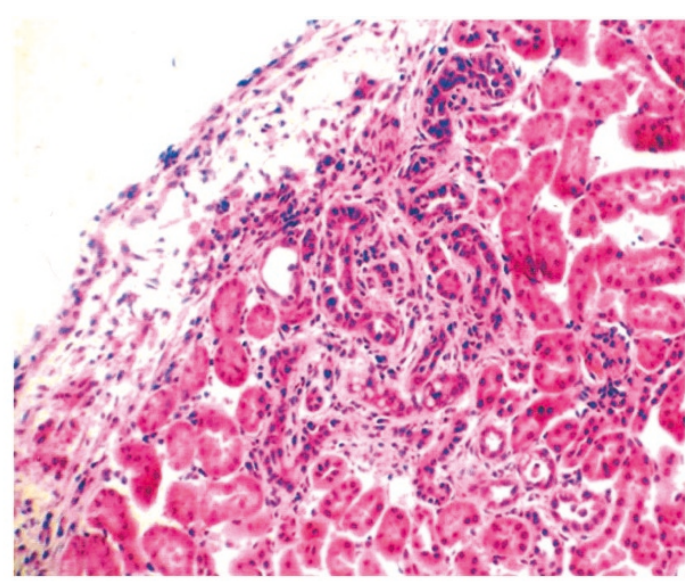

B

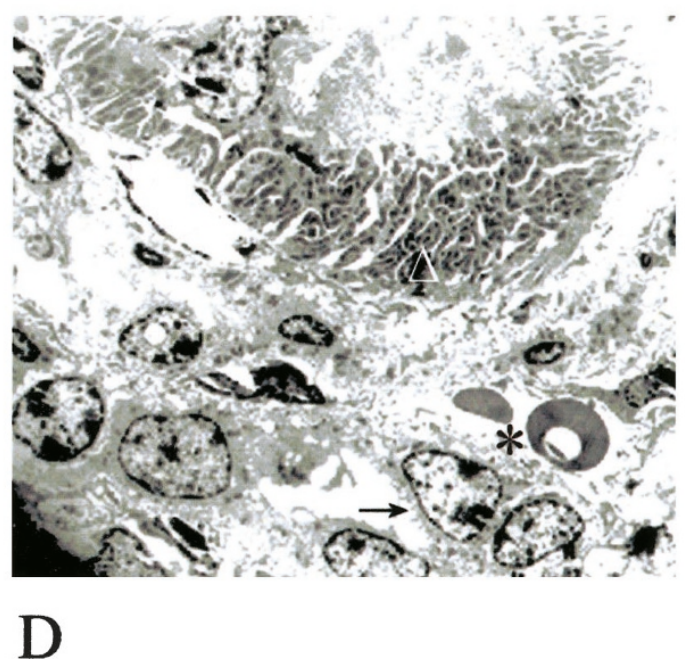

Figure 6.

In vivo phenotypic analysis of NIPs. A, Reversal of hyperglycemia in diabetic mice $(n=8)$. All NOD-Scid mice became hyperglycemic 3 days after STZ treatment Blood glucose levels of implanted group approached normal 4 days after 500 ICCs were implanted and were kept stable up to 40 days, whereas the STZ group showed persistent hyperglycemia. Normal mice without any treatment were selected as control. ${ }^{\star} p<0.05$ denotes a significant difference when compared with values of STZ group on the same day. B to D, ICCs implanted in normal NOD-Scid mice overproliferated and infiltrated into renal parenchyma. B, Histologic sections of kidney stained with H\&E showed that NIPs formed various structures and infiltrated from implant site to renal parenchyma (200×). C, Ultrastructural study of subcapsular region showed cell clusters and duct structures $\left(^{*}\right)(1600 \times)$. D, Renal parenchymal ultrastructure showed that duct-like structures with microvillus $(\rightarrow)$ formed adjacent to renal tubule $(\triangle)$ and blood vessel $\left({ }^{*}\right)(2100 \times)$.

provide promising evidence that ICCs of stage 3 produce adequate insulin in vivo and function in reducing the blood glucose level of diabetic mice.

As control, ICCs of stage 3 were implanted into three normal NOD-Scid mice. Kidneys were removed 40 days after implantation. Histologic sections of implant sites showed that ICCs coalesced to form a large mass that infiltrates the renal parenchyma and forms various structures that seem to be ducts, small compact cell clusters, blood vessels, and scattered cells (Fig. 6B). Ultrastructural studies of the subcapsular region (Fig. 6C) and renal parenchyma further demonstrated this infiltration (Fig. 6D), and such phenomena were found in all implant sites of normal mice.

\section{Discussion}

The present study provides evidence that NIPs derived from human fetal pancreas are multipotential and have the capacity to differentiate into functional $\beta$ cells. This is consistent with adult NIPs (Abraham et al, 2002; Ramiya et al, 2000; Zulewski et al, 2001) and ES-derived nestin-positive cells (Lumelsky et al, 2001). Nestin was initially found in neural stem cells (Lendahl et al, 1990) and later in myoblast and pancreatic precursors and (Hunziker and Stein, 2000; Wroblewski et al, 1997). Nestin-positive cells harbored in pancreatic ducts and islets are similar to other multipotential stem cells both in proliferation behavior and on a molecular level, and that their number increases greatly in regenerating adult pancreas suggests a contribution in the process of pancreas regeneration (Lardon et al, 2002). In addition, it was reported that nestin-positive cells in pancreas were found in the stroma of pancreatic ducts and common in connective tissue, as well as in the islets (Selander and Edlund, 2002). These cells were also found in endothelial cells 
from neocapillaries and in hepatic stellate cells (Niki et al, 1999). Additional studies are required to determine conclusively whether heterogeneity in the population of nestin-positive cells is the cause of the current controversy and whether NIPs generate insulinproducing cells by trans-differentiation.

During the process of expansion and differentiation, the culture conditions were changed several times. Relatively low concentrations of serum and bFGF were applied for expansion of NIPs, as low concentration of serum is essential for preventing neural stem cells from differentiation (Gage, 2000; Okabe et al, 1996). In addition, bFGF is mitogenic for neural stem cells (Vescovi et al, 1993), and attenuation of bFGF signaling pathway might cause diabetes (Hart et al, 2000). Besides removal of bFGF, induction of differentiation of NIPs depends mainly on two factors: a concomitant increase in the concentration of glucose, a main regulator for the maturation of $\beta$ cells (Melloul and Cerasi, 1994; Rosenberg and Vinik, 1992), and the particular niche in three-dimensional ICC structures. The microenvironment, known as a "niche," is essential for certain stem cells to proliferate and differentiate. It is believed that niche is more important than cell lineage history (Spradling et al, 2001). Niches control stem cells by signals and interactions between cells. Three-dimensional structure made up by extra cellular matrigel is an in vitro niche in which islets are formed from ducts (Bonner-Weir et al, 2000). In our study, the three-dimensional ICC structures formed during NIP differentiation resemble morphologically those described by other researchers (Bonner-Weir et al, 2000; Ramiya et al, 2000; Yang et al, 2002; Zulewski et al, 2001). ICCs may provide cell-cell interactions and an appropriate niche for the differentiation of human fetal NIPs. We encountered the problem of incomplete induction, which is a common difficulty in studies of stem cells. Even at end stage of differentiation, some undifferentiated cells and other cell types remain. Additional efforts to optimize conditions and enhance the efficiency of induction are under way.

In our culture of NIPs, genes encoding pancreatic proteins are activated sequentially. In their undifferentiated stage, NIPs are nestin and ABCG2 positive but PDX-1 and insulin negative. Our detection of ABCG2 expression in human fetal pancreatic NIPs is in agreement with a recent report that indicates side population cells in adult pancreas (Lechner et al, 2002). ABCG2 expression had also been previously detected in ES cells, hematopoietic stem cells, muscle stem cells, marrow stem cells (Geschwind et al, 2001; Zhou et al, 2001), neural stem cells (Geschwind et al, 2001), and premature hematopoietic progenitor cells (Scharenberg et al, 2002). It has been speculated that ABCG2 may pump differentiation factors out of the cell to keep the cell in an undifferentiated state (Scharenberg et al, 2002). When NIPs begin to differentiate and form ICCs, tissue-specific genes expressed at this stage include pancreatic markers such as PDX-1, GLUT-2, glucagon, and AMY. Transcription of insulin is undetectable in ICCs until further induced. It is interesting that $P D X-1$ expression falls at stage 3 , and this drop may be predictable as it was previously demonstrated that transcript of $P D X-1$ is undetectable in the islets of adult rodents (Stoffers et al, 1999). Similar phenomena were also observed in ES-derived insulin-secreting cells (Lumelsky et al, 2001) and transdifferentiated adult hepatic stem cells (Yang et al, 2002). Despite this down-regulation of PDX-1, which may be due to posttranscriptional control (Stoffers et al, 1999), $\beta$-cell phenotype was reconfirmed by detecting transcripts of various $\beta$-cell markers such as insulin, Nkx6.1, and Isl1. In addition, c-MET maintained high levels throughout differentiation, and because c-MET is closely related to cell mobility, it may contribute to aggregation of NIPs and formation of ICCs. Semiquantitative RT-PCR showed that differentiation of NIPs correlate well with the down-regulation of $A B C G 2$ and nestin, suggesting that nestin may have important roles in keeping stem cells from differentiation as ABCG2 does. The coexpression of nestin and $A B C G 2$ demonstrated herein warrants additional studies and might indicate a broader role for nestin as a general marker of stem/progenitor cells.

Stem cells have offered much hope, and stem cell therapies in animal experiments have been proved as an effective alternative. As human disease treatment must be both safe and effective, safety should be considered as an issue of priority. One safety issue is that tumors may originate from the transformation of stem cells. Similar signaling pathways may also regulate self-renewal in stem cells and cancer cells, and the latter may include "cancer stem cells" (Reya et al, 2001). ABCG2, a member of ABC (ATP binding cassette transporter) superfamily, not only is responsible for multidrug resistance in many cancer cell lines (Ross et al, 1999) but also is found to help maintain the unique properties of stem cells (Zhou et al, 2001). It is possible that $A B C G 2$ is one of the molecules that may implicate stem cells with cancer. When we implanted stage 3 ICCs into normal NOD-Scid mice, they overproliferated and infiltrated into renal parenchyma. Tumor-like structures were observed, but the expansion velocity is slower than tumor cells. It is notable that no infiltrating cells were found in diabetic mice that received with stage 3 ICCs, possibly because of stimulated differentiation of NIPs under the specific environment in diabetic mice. The most important factor may be glucagon-like peptide-1 (GLP-1), which was found with a robust increase in STZ-induced diabetic rats and may play a role in neogenesis of $\beta$ cells (Nie et al, 2000). Recently, GLP-1 was used successfully to induce differentiation of NIPs into insulin-producing cells (Abraham et al, 2002). Other factors may include concentrated blood glucose, a main regulator during maturation of pancreatic $\beta$ cells (Leibowitz et al, 2001), and serum from diabetic mice, which was used as the main inductive factor in in vitro cultured pancreatic stem cells (Cornelius et al, 1997). It is widely known that ES cells are capable of forming tumors in vivo; similar tumor-forming ability has not been observed in adult stem cells until now. Thus, additional research is needed to determine whether the overproliferation found in our study is malignant. 


\section{Materials and Methods}

\section{Isolation, Culture, and Induction of NIPS}

Twelve- to 21-week-old human fetal pancreata were collected at the Obstetrical and Gynecological Hospital of Fudan University. Gestational age was determined by several previously described criteria (Mercer et al, 1987; Streeter, 1920). Freshly obtained pancreata were washed three times in PBS, extraneous material was carefully dissected away, and pancreata were minced gently into smaller fragments. After a single wash in HBSS containing $10 \mathrm{~mm}$ HEPES to remove blood cells, the fragments were subjected to $5.5 \mathrm{mg} / \mathrm{ml}$ collagenase IV in a shaking water bath $\left(37^{\circ} \mathrm{C}\right)$. Duct and primary cell clusters were confirmed by inverted microscopy. The collagenase was then purged by centrifugation, followed by a single wash in cold HBSS. Duct and primary cell clusters were subsequently handpicked and placed into a tissue culture flask containing EHAA medium supplemented with $2 \%$ FBS. After a 48 -hour incubation at $37^{\circ} \mathrm{C}$ with $5 \%$ $\mathrm{CO}_{2}$, most cells attached to the bottom and slightly spread out. For selecting nestin-positive cells, adherent cells were further cultured in DMEM (without glucose) supplemented with $0.5 \%$ FBS and were incubated undisturbed for 3 to 4 weeks until the majority of the original cells died. The remaining live cells were then half refreshed by DMEM/F12 $(11.1 \mathrm{~mm}$ glucose) supplemented with $10 \%$ FBS and $20 \mathrm{ng} / \mathrm{ml}$ bFGF to favor expansion. Cells proliferated rapidly and were maintained for approximately 1 year by serial splits before reaching confluence. For inducing differentiation, NIPs were cultured in DMEM/F12 containing high glucose (16.5 mm) and cocktail of several growth factors, including $10 \mathrm{ng} / \mathrm{ml}$ IGF, $500 \mathrm{pmol} / \mathrm{L}$ betacellulin, $10 \mathrm{ng} / \mathrm{ml} \mathrm{HGF}$, and $10 \mathrm{~mm}$ nicotinamide.

\section{Immunohistochemistry}

ICCs of various stages were fixed for 2 hours in $4 \%$ paraformaldehyde and embedded in OCT. Cryosections were stained by the ABC method according to standard protocols. The following antibodies were used after dilution: mouse anti-human nestin antibody (1:100; Chemicon), monoclonal anti-insulin (1:1000; Sigma), monoclonal anti-glucagon (1:2000; Sigma), monoclonal anti-cytokeratin peptide 19 (1:50; Sigma), FITC-conjugated affinipure donkey anti-mouse $\lg \mathrm{G}(\mathrm{H}+\mathrm{L})$ (1:200; Jackson), and biotin-Sp-conjugated affinipure goat anti-mouse $\lg \mathrm{G}(\mathrm{H}+\mathrm{L})$ (1:500; Jackson). Detection was accomplished using Streptavidin/ Streptavidine HRP (1:200; Dako). The reaction substrate was DAB (Sangon). BSA was used in place of primary antibodies on control slides. Counterstaining was carried out with hematoxylin, and fluorescent images were obtained using a Zeiss LSM-510 laser confocal microscope.

\section{Measurement of Intracellular and Secreted Insulin by Immunoenzymatic Assay}

For determining total cellular insulin content, insulin was extracted from ICCs and equal amount of primar- ily cultured human fetal islets. Cells were treated with lysis buffer, followed by cell sonication. For insulin secretion assay, 300 ICCs of stage 3 were incubated in medium for 1 week, washed twice with serum-free medium, and then stimulated for 2 hours in serum-free medium containing glucose of various concentrations. In addition, ICCs were challenged by $5 \mathrm{~mm}$ glucose in conjunction with $1 \mathrm{~mm}$ tolbutamide, $1 \mathrm{~mm}$ carbachol, and $1 \mathrm{~mm}$ glucagon-like peptide-1, respectively. Supernatants were collected for the insulin secretion detection. Insulin concentrations were measured by magnetic solid-phase enzyme immunoassay (Insulin Serozyme kit; Bio-Ekon Diagnostics Products). The reagent is highly specific for the detection of human insulin, and cross-reaction to proinsulin or c-peptide is $<0.01 \%$.

\section{RT-PCR Assay}

Total RNA was prepared from cultured NIPs and ICCs using Trizol (GIBCO). After purification and reverse transcription, the cDNA was amplified by PCR for 30 cycles. Primer sets were designed on the basis of published reports or GenBank and synthesized by Sangon Company. Forward and reverse primer sequences from 5 ' to $3^{\prime}$ direction and the lengths of the amplified products were as follows: PDX-1, GGATGAAGTCTACCAAAGCTCACGC,CCAGATCTTGAT GTGTCTCTCGGTC (218bp); Amylase, GCTGGGC TCAGTATTCCCCAAATAC,GACGACAATCTCTGA CCTG AGTAGC (492 bp); $\beta$-actin, TGGCACCACACCTTCTACAATGAGC, GCACAGCTTCTCCTTAATGTCACGC (396 bp); CK19, AGGAAATCATCTCAGGAGGAAGGGC, AAA GCACAGATCTTCGGGAGCTACC (783 bp); somatostatin, GTTCTGCAGAAGTCTCGG, AGTTCTTGCAGCCAGCT TTG (223 bp); nestin, AGAGGGGAATTCCTGGAG, CTGAGGACCAGGACTCTCTA (495 bp); HGF, GCATCAAATGTCAGCCCTGGG, CAACGCTGACATGGAATTCC (534 bp); c-MET, CAATGTGAGATGTCTCCAGC, CCTTGTAGATTGCAGGCAGA (559bp); GLUT2, GCAGCTGCTCAACTAATCAC, TCAGCAGCACAAGTCCCACT (909bp); insulin, TCACACCTGGTGGAAGCTC, ACAATGCCAC GCTTCTGC (179bp); Nkx6.1, GATCCATTTTGTTGGACAAAGA, CACGGCCAAGAAGAGGCAGGACT (221 bp); Is/1, CTTAAATTGGACTCCTAGAT, GGATTTGGAATGGCATGCGG (280 bp); ABCG2/BCRP1, GGCCTCAGGAAGACTTATGT, AAGGAGGTGGTGTAGCTGAT (342bp). The annealing temperature was $50^{\circ} \mathrm{C}$ for $P D X-1$ and insulin; $51.5^{\circ} \mathrm{C}$ for $\mathrm{CK} 19$, Is 11 , and GLUT-2; $52.5^{\circ} \mathrm{C}$ for somatostatin and $N K X 6.1 ; 53.5^{\circ} \mathrm{C}$ for $A M Y$ and nestin; $56.5^{\circ} \mathrm{C}$ for HGF and $A B C G 2 / B C R P 1 ; 57.5^{\circ} \mathrm{C}$ for actin; and $60^{\circ} \mathrm{C}$ for $C-M E T$. Agarose gel (1.7\%) was used to separate the PCR products.

Semiquantitative RT-PCR assay of both ABCG2 and nestin transcripts was performed by amplification of the $\beta$-actin normalized RT reactions along with quantitative standards. Amplified product values were normalized to $\beta$-actin for intersample comparisons or to standard curves for intergene comparisons within a given sample. 


\section{Transplantation Studies}

NOD-Scid mice obtained from Jackson Laboratory were bred and maintained in the IVC (individual cage) mouse facility of the Department of Laboratory Animal Science of Shanghai Second Medical University. Eight- to 12-week-old male mice were selected for allogenic transplantations. All animal studies were in accordance with Shanghai Second Medical University institutional guidelines. Sixteen mice were divided into two groups: (a) the group that received implant and (b) the STZ group. Experimental diabetes was induced by a single intraperitoneal injection of STZ as previously described (Lumelsky et al, 2001). Briefly, STZ (Sigma) was freshly dissolved in $0.1 \mathrm{M}$ of citrate buffer $(\mathrm{pH} 7.4)$ and injected into NOD-Scid mice at a dose of 150 $\mathrm{mg} / \mathrm{kg}$ body weight. Blood glucose level was determined with a blood glucose monitor and lancing device (Roche, GLUCOTREND soft test system). After a stable level of hyperglycemia was reached (typically 48 to 72 hours), animals were prepared to receive implants. Eight NOD-Scid mice were anesthetized by injecting $600 \mu \mathrm{l}$ of $2.5 \%$ pentobarbital sodium. The left kidney was exposed through a small incision in the flank, and approximately 500 ICCs of stage 3 were implanted into the subcapsular region via a small glass catheter, and the incision was closed by suture. STZtreated NOD-Scid mice received an implant of physiologic saline as a control. Eight normal NOD-Scid mice did not receive any treatment as control. For investigating the in vivo potential of NIPs, an equal amount of stage 3 ICCs were implanted into normal NOD-Scid mice. All animals were killed 40 days after the procedure, and the left kidneys were excised and were fixed in $4 \%$ paraformaldehyde and $2 \%$ glutaraldehyde for further research.

\section{Ultrastructural Analysis}

Kidneys of normal NOD-Scid mice were excised 40 days after ICCs were implanted, and were fixed with $2 \%$ glutaraldehyde, postfixed with $1 \% \mathrm{OsO}_{4}$, dehydrated in graded acetone solutions, and embedded in epoxy resin 618 . Ultrathin sections were cut with a Leica Ultracut $R$ and counterstained with uranium acetate and lead citrate. Ultrastructural study was performed using a Philip CM120 TEM.

\section{Statistical Analysis}

Results are expressed as means \pm SEM. Statistical analysis of the data was performed using Student's $t$ test. $p<0.05$ was considered to be significant. Statistics software used is SAS 6.2.

\section{Acknowledgements}

We gratefully acknowledge Yixin Wu (the Institute of Endocrinology, Shanghai Second Medical University), Yuying Chen, Hui Cang, Xinzhi Huang, and Xinyu Chen for excellent technical assistance and the laboratory staff of our department for scientific discussions.

\section{References}

Abraham EJ, Leech CA, Lin JC, Zulewski H, and Habener JF (2002). Insulinotropic hormone glucagon-like peptide-1 differentiation of human pancreatic islet-derived progenitor cells into insulin-producing cells. Endocrinology 143:31523161 .

Arias AE and Bendayan M (1993). Differentiation of pancreatic acinar cells into duct-like cells in vitro. Lab Invest 69:518-530.

Bonner-Weir S, Baxter LA, Schuppin GT, and Smith FE (1993). A second pathway for regeneration of adult exocrine and endocrine pancreas. A possible recapitulation of embryonic development. Diabetes 42:1715-1720.

Bonner-Weir S, Taneja M, Weir GC, Tatarkiewicz K, Song KH, Sharma A, and O'Neil JJ (2000). In vitro cultivation of human islets from expanded ductal tissue. Proc Natl Acad Sci USA 97:7999-8004.

Cornelius JG, Tchernev V, Kao KJ, and Peck AB (1997). In vitro-generation of islets in long-term cultures of pluripotent stem cells from adult mouse pancreas. Horm Metab Res 29:271-277.

Fernandes A, King LC, Guz Y, Stein R, Wright CV, and Teitelman $G$ (1997). Differentiation of new insulin-producing cells is induced by injury in adult pancreatic islets. Endocrinology 138:1750-1762.

Finegood DT, Scaglia L, and Bonner-Weir S (1995). Dynamics of beta-cell mass in the growing rat pancreas. Estimation with a simple mathematical model. Diabetes 44:249-256.

Gage FH (2000). Mammalian neural stem cells. Science 287:1433-1438.

Geschwind DH, Ou J, Easterday MC, Dougherty JD, Jackson RL, Chen Z, Antoine H, Terskikh A, Weissman IL, Nelson SF, and Kornblum HI (2001). A genetic analysis of neural progenitor differentiation. Neuron 29:325-339.

Gmyr V, Kerr-Conte J, Belaich S, Vandewalle B, Leteurtre E, Vantyghem MC, Lecomte-Houcke M, Proye C, Lefebvre J, and Pattou F (2000). Adult human cytokeratin 19-positive cells reexpress insulin promoter factor 1 in vitro: Further evidence for pluripotent pancreatic stem cells in humans. Diabetes 49:1671-1680.

Guz Y, Nasir I, and Teitelman G (2001). Regeneration of pancreatic beta cells from intra-islet precursor cells in an experimental model of diabetes. Endocrinology 142:49564968.

Hart AW, Baeza N, Apelqvist A, and Edlund H (2000). Attenuation of FGF signalling in mouse beta-cells leads to diabetes. Nature 408:864-868.

Hunziker E and Stein M (2000). Nestin-expressing cells in the pancreatic islets of Langerhans. Biochem Biophys Res Commun 271:116-119.

Lardon J, Rooman I, and Bouwens L (2002). Nestin expression in pancreatic stellate cells and angiogenic endothelial cells. Histochem Cell Biol 117:535-540.

Lechner A, Leech CA, Abraham EJ, Nolan AL, and Habener JF (2002). Nestin-positive progenitor cells derived from adult human pancreatic islets of Langerhans contain side population (SP) cells derived by expression of ABCG2(BCRP1) ATP-binding cassette transporter. Biochem Biophys Res Commun 293:670-674. 
Leibowitz G, Ferber S, Apelqvist A, Edlund H, Gross DJ, Cerasi E, Melloul D, and Kaiser N (2001). IPF1/PDX1 deficiency and beta-cell dysfunction in Psammomys obesus, an animal with type 2 diabetes. Diabetes 50:1799-1806.

Lendahl U, Zimmerman LB, and McKay RD (1990). CNS stem cells express a new class of intermediate filament protein. Cell 60:585-595.

Lumelsky N, Blondel O, Laeng P, Velasco I, Ravin R, and McKay R (2001). Differentiation of embryonic stem cells to insulin-secreting structures similar to pancreatic islets. Science 292:1389-1394.

Melloul D and Cerasi E (1994). Transcription of the insulin gene: Towards defining the glucose-sensitive cis-element and trans-acting factors. Diabetologia 37(Suppl 2):S3-S10.

Mercer BM, Sklar S, Shariatmadar A, Gillieson MS, and D'Alton ME (1987). Fetal foot length as a predictor of gestational age. Am J Obstet Gynecol 156:350-355.

Nie Y, Nakashima M, Brubaker PL, Li QL, Perfetti R, Jansen E, Zambre Y, Pipeleers D, and Friedman TC (2000). Regulation of pancreatic PC1 and PC2 associated with increased glucagon-like peptide 1 in diabetic rats. J Clin Invest 105: 955-965.

Niki T, Pekny M, Hellemans K, Bleser PD, Berg KV, Vaeyens F, Quartier E, Schuit F, and Geerts A (1999). Class VI intermediate filament protein nestin is induced during activation of rat hepatic stellate cells. Hepatology 29:520-527.

Okabe S, Forsberg-Nilsson K, Spiro AC, Segal M, and McKay RD (1996). Development of neuronal precursor cells and functional postmitotic neurons from embryonic stem cells in vitro. Mech Dev 59:89-102.

Otonkoski T, Beattie GM, Rubin JS, Lopez AD, Baird A, and Hayek A (1994). Hepatocyte growth factor/scatter factor has insulinotropic activity in human fetal pancreatic cells. Diabetes 43:947-953.

Ramiya VK, Maraist M, Arfors KE, Schatz DA, Peck AB, and Cornelius JG (2000). Reversal of insulin-dependent diabetes using islets generated in vitro from pancreatic stem cells. Nat Med 6:278-282.

Reya T, Morrison SJ, Clarke MF, and Weissman IL (2001). Stem cells, cancer, and cancer stem cells. Nature 414:105111.

Rosenberg L (1995). In vivo cell transformation: Neogenesis of beta cells from pancreatic ductal cells. Cell Transplant 4:371-383.

Rosenberg $L$ and Vinik Al (1992). Trophic stimulation of the ductular-islet cell axis: A new approach to the treatment of diabetes. Adv Exp Med Biol 321:95-104; discussion 105109.

Ross DD, Yang W, Abruzzo LV, Dalton WS, Schneider E, Lage H, Dietel M, Greenberger L, Cole SP, and Doyle LA (1999). Atypical multidrug resistance: Breast cancer resistance protein messenger RNA expression in mitoxantroneselected cell lines. J Natl Cancer Inst 91:429-433.
Scharenberg CW, Harkey MA, and Torok-Storb B (2002). The ABCG2 transporter is an efficient Hoechst 33342 efflux pump and is preferentially expressed by immature human hematopoietic progenitors. Blood 99:507-512.

Schwitzgebel VM, Scheel DW, Conners JR, Kalamaras J, Lee JE, Anderson DJ, Sussel L, Johnson JD, and German MS (2000). Expression of neurogenin3 reveals an islet cell precursor population in the pancreas. Development 127:35333542.

Selander $L$ and Edlund $H$ (2002). Nestin is expressed in mesenchymal and not epithelial cells of the developing mouse pancreas. Mech Dev 113:189-192.

Spradling A, Drummond-Barbosa D, and Kai T (2001). Stem cells find their niche. Nature 414:98-104.

Stoffers DA, Heller RS, Miller CP, and Habener JF (1999). Developmental expression of the homeodomain protein IDX-1 in mice transgenic for an IDX-1 promoter/lacZ transcriptional reporter. Endocrinology 140:5374-5381.

Streeter GL (1920). Weight, sitting height, head size, foot length, and menstrual age of the human embryo. Contrib Embryol Carnegie Inst 11:143-148.

Vescovi AL, Reynolds BA, Fraser DD, and Weiss S (1993). bFGF regulates the proliferative fate of unipotent (neuronal) and bipotent (neuronal/astroglial) EGF-generated CNS progenitor cells. Neuron 11:951-966.

Wroblewski J, Engstrom M, Edwall-Arvidsson C, Sjoberg G, Sejersen T, and Lendahl U (1997). Distribution of nestin in the developing mouse limb bud in vivo and in micro-mass cultures of cells isolated from limb buds. Differentiation 61:151-159.

Yang L, Li S, Hatch H, Ahrens K, Cornelius JG, Petersen BE, and Peck $A B$ (2002). In vitro trans-differentiation of adult hepatic stem cells into pancreatic endocrine hormoneproducing cells. Proc Natl Acad Sci USA 99:8078-8083.

Zhou S, Schuetz JD, Bunting KD, Colapietro AM, Sampath J, Morris JJ, Lagutina I, Grosveld GC, Osawa M, Nakauchi H, and Sorrentino BP (2001). The ABC transporter Bcrp1/ ABCG2 is expressed in a wide variety of stem cells and is a molecular determinant of the side-population phenotype. Nat Med 7:1028-1034.

Zulewski H, Abraham EJ, Gerlach MJ, Daniel PB, Moritz W, Muller B, Vallejo M, Thomas MK, and Habener JF (2001). Multipotential nestin-positive stem cells isolated from adult pancreatic islets differentiate ex vivo into pancreatic endocrine, exocrine, and hepatic phenotypes. Diabetes 50:521533. 